\title{
How many inpatients in our hospitals have foot complications? The Foot Disease in Inpatients Study
}

\author{
Peter A Lazzarini ${ }^{1,2,3^{*}}$, Vanessa $\mathrm{Ng}^{2,3}$, Suzanne S Kuys ${ }^{2,4}$, Maarten C Kamp ${ }^{1,5}$, Michael C d'Emden ${ }^{5,6}$, \\ Courtney Thomas ${ }^{7}$, Jude Wills ${ }^{8}$, Ewan M Kinnear ${ }^{2,3}$, Scott Jen ${ }^{9}$, Sheree E Hurn ${ }^{1}$, Lloyd Reed ${ }^{1}$ \\ From Australasian Podiatry Conference 2015 \\ Queensland, Australia. 6-8 May 2015
}

\section{Background}

Foot complications have been found to affect large proportions of hospital in patients with diabetes. However, no studies have investigated the proportion of foot complications affecting all people in general inpatient populations. The aims of this cross-sectional study were to investigate the point-prevalence of different foot complications in general inpatient populations, analyse differences in diabetes and non-diabetes sub-groups, and examine characteristics of people primarily admitted for a foot complication.

\section{Methods}

Eligible participants were all adults admitted overnight, for any reason, into five diverse hospitals on one day; excluding maternity, mental health and cognitively impaired patients. All participants underwent a physical foot examination, by trained podiatrists using validated measures, to clinically diagnose different foot complications; including foot wounds, infections, deformity, peripheral arterial disease (PAD) and peripheral neuropathy $(\mathrm{PN})$. Data were also collected on participants' primary reason for admission and a range of demographic, social determinant, medical history, foot complication history, self-care and footwear risk factors.

\section{Results}

Overall, 733 participants consented (83\% of eligible participants); mean $( \pm \mathrm{SD})$ age $62( \pm 19)$ years, $480(55.8 \%)$ male and $172(23.5 \%)$ had diabetes. Foot complication prevalence included: wounds $9.0 \%(95 \% \mathrm{CI})(5.1-8.7)$,

\footnotetext{
* Correspondence: Peter.Lazzarini@health.qld.gov.au

'School of Clinical Sciences, Queensland University of Technology, Brisbane, Queensland, 4059, Australia

Full list of author information is available at the end of the article
}

infections $3.3 \%$ (2.2-4.9), deformity $22.4 \%$ (19.5-26.7), PAD 21.0\% (18.2-24.1) and PN 22.0\% (19.1-25.1). Diabetes populations had significantly more foot complications than non-diabetes $(p<0.01)$; wounds $(15.7 \%$ vs $7.0 \%$ ), infections $(7.1 \%$ vs $2.2 \%)$, deformity ( $30.5 \%$ vs $19.9 \%)$, PAD (35.1\% vs $16.7 \%)$ and PN (43.3\% vs $15.4 \%)$. Foot complications were the primary reason for admission in $7.4 \%$ (95\% CI) (5.7-9.5) of all participants. In a backwards stepwise multivariate analysis having a foot complication as the primary reason for admission was independently associated (OR (95\% CI) with foot wounds (18.9 (7.3-48.7)), foot infections (6.0 (1.6-22.4)), history of amputation (4.7 (1.3-17.0) and PAD (2.9 (1.3-6.6)).

\section{Conclusions}

Findings of this study indicate one in every ten hospital inpatients had an active foot wound or infection. In patients with diabetes had significantly higher proportions of foot complications than non-diabetes inpatients. Remarkably one in every thirteen inpatients in this study were primarily hospitalised for a foot complication. Further research and policy is required to tackle this seemingly large inpatient foot complication burden.

\footnotetext{
Authors' details

'School of Clinical Sciences, Queensland University of Technology, Brisbane, Queensland, 4059, Australia. ${ }^{2}$ Allied Health Research Collaborative, Metro North Hospital \& Health Service, Queensland Health, Brisbane, Queensland, 4032, Australia. ${ }^{3}$ Department of Podiatry, Metro North Hospital \& Health Service, Queensland Health, Brisbane, Queensland, 4032, Australia. ${ }^{4}$ Musculoskeletal Research Program, Griffith Health Institute, Griffith University, Gold Coast, Queensland, 4222, Australia. ${ }^{5}$ Department of Endocrinology and Diabetes, Royal Brisbane and Womens Hospital, Brisbane, Queensland, 4029, Australia. ${ }^{6}$ School of Medicine, The University of Queensland, Brisbane, Queensland, 4072, Australia. 'Department of Podiatry, North West Hospital \& Health Service, Mount Isa, Queensland, 4825, Australia.
} 
${ }^{8}$ Department of Podiatry, Central Queensland Hospital \& Health Service, Rockhampton, Queensland, 4700, Australia. ${ }^{9}$ Department of Podiatry, West Moreton Hospital \& Health Service, Queensland Health, Ipswich, Queensland, 4305, Australia.

Published: 22 September 2015

doi:10.1186/1757-1146-8-S2-025

Cite this article as: Lazzarini et al:. How many inpatients in our hospitals have foot complications? The Foot Disease in Inpatients Study. Journal of Foot and Ankle Research 2015 8(Suppl 2):O25.

Submit your next manuscript to BioMed Central and take full advantage of:

- Convenient online submission

- Thorough peer review

- No space constraints or color figure charges

- Immediate publication on acceptance

- Inclusion in PubMed, CAS, Scopus and Google Scholar

- Research which is freely available for redistribution

Submit your manuscript at www.biomedcentral.com/submit 